\title{
Evidence in Support of Removing Boundaries to Undergraduate Research Experience
}

\author{
Neil Haave \& Doris Audet \\ University of Alberta
}

Undergraduate research is one of several high impact educational practices used by educational institutions to increase student engagement and success (Kuh, 2008). Many studies on the impact of undergraduate research have surveyed students or faculty on their personal experience and its influence on students' subsequent degrees and employment (Brownell \& Swaner, 2010). These studies have documented the ability of high impact educational practices to have the greatest influence on those students who self-identify as belonging to a minority or disadvantaged group. Few studies, however, have documented the impact on students with lower grades. The privilege of being admitted to an undergraduate research experience (e.g., an independent studies course) is typically reserved for upper-year students who have proven themselves academically. This paper presents correlational data from our campus showing that academically weaker students have a greater increase in academic performance between prior grade point average (GPA) and final grade in an independent studies course than academically stronger students. In addition, student annual GPA data shows that the impact of undergraduate research serves to raise students' GPAs in the year of an independent studies course. Although the findings are based on data from one small campus, they do raise the question that if undergraduate research has the greatest impact on academically weaker students and accelerates academic maturity, is limiting registration into these courses on the basis of superior GPA and years of study placing inappropriate boundaries on student learning?

\section{Introduction}

$\mathrm{U}$ ndergraduate research is one of several high impact practices used by educational institutions to increase student engagement and success (Kuh, 2008). Lopatto (2007) writes that it enhances students' independence, intrinsic motivation to learn, and active participation in subsequent courses. Access to undergraduate research, however, has been limited to those with superior grade point average (GPA) (Harde \& Haave, 2012). Many studies on the impact of undergraduate research have surveyed students or faculty on their personal experience and its influence on students' subsequent degrees and employment in addition to increasing retention of students in their degree program and contributing to students' emerging sense of self-identity (Brongo Pacifici 
\& Thomson, 2011; Brownell \& Swaner, 2010; Marcus, Hughes, \& McElroy, 2010; Nagda, Gregerman, Jonides, Von Hippel \& Lerner, 1998; Seymour, Hunter, Laursen, \& Deantoni, 2004). Brownell and Swaner (2010) have shown that, as a high impact practice, undergraduate research seems to have the greatest influence on those students who self-identify as belonging to a minority or disadvantaged group. Current research suggests that the reason undergraduate research has a high impact on student outcomes is that it engages students at a higher epistemic level causing students to consider the science act (i.e., what, how, and why they are investigating a particular question) beyond following a set of instructions as is common in more traditional courses with an accompanying lab (Brongo Pacifici \& Thomson, 2011; Sadler \& McKinney, 2010). Other studies have demonstrated that undergraduate research courses produced significantly higher GPAs, and that engaging in more than one undergraduate research course has greater impact on increasing graduating GPA even though students themselves do not realize prior to engaging in an undergraduate research experience the degree to which their GPA will be positively affected (Brongo Pacifici \& Thomson, 2011; Fechheimer, Webber, \& Kleiber, 2011; Jonides, 1995; Kinkel \& Henke, 2006). No studies, however, have documented the impact on students in general with lower grades or whether the impact is observable prior to graduation.

\section{Our Study}

For our study, we asked the following two questions:

1. Do students with lower GPAs gain greater benefits from undergraduate research?

2. Are any differences long lasting?

Although undergraduate research experiences (UREs) can take on a number of forms for students (e.g., summer student research assistants, independent studies courses), for the purposes of this study we defined a URE as an independent studies course because this allowed us to use the grade earned to examine the effects of a URE.

\section{Do students with lower GPAs gain greater benefits from undergraduate research?}

To answer this question, we gathered data for 201 students enrolled in undergraduate research experiences between 2006 and 2011 at the Augustana Campus, a Liberal Arts and Sciences Faculty, of the University of Alberta. Students were enrolled in a variety of programs from the Fine Arts, Sciences, Social Sciences and Humanities. For the purposes of this study, we assumed that an undergraduate research experience was encountered in any independent studies course (e.g., directed reading, directed studies, etc.). We analyzed the relationship between students' cumulative GPA prior to the URE and their final mark in that course.

In our sample, on a 4-point scale, students' GPAs prior to an independent studies course were skewed toward higher values (> 3.2, $\mathrm{N}=123$ students) although a substantial number of students $(\mathrm{N}=78)$ with lower GPA ( $\leq$ 3.2) took part in those courses (Figure 1a). In our analyses, we used that mean value of GPA as a threshold between the higher GPA student group (GPA > 3.2) and the lower GPA student group $(\leq 3.2)$ when making comparisons between groups. Mean values are expressed \pm one standard deviation (SD) and P values under the threshold of 0.05 in statistical analyses are considered significant.

Independent studies course grades were generally higher than prior GPAs (Figure 1b) and students across the full range of GPA achieved high URE grades (Figure 2). Even though the higher GPA student group achieved significantly higher mean course grades (higher GPA group $=3.89 \pm 0.22$, lower GPA group $=3.48 \pm 0.8$, Mann-Whitney U-test, $\mathrm{P}<0.001$ ), the relative benefits of undergraduate research, measured by the difference between a student's prior GPA and their independent studies course grade (URE - GPA), were greater for students with lower GPAs (Figure 2). For this group, mean URE was $0.80 \pm 0.83$ points higher than their prior GPA, in comparison to $0.27 \pm 0.27$ for the higher GPA student group. Those differences are strongly significant (MannWhitney U-test, $\mathrm{P}<0.001)$ as $\mathrm{P}$ values below the threshold of 0.05 are considered significant. In fact, $65.5 \%$ of students from the lower GPA group achieved $\geq 3.7$ (i.e. in the $\mathrm{A}^{-}-\mathrm{A}^{+}$range) in their URE course grade. What this suggests is that academically weaker students (as defined by their prior GPA) perform better in a URE than would be expected based in relation to their prior GPA.

\section{Are the differences long lasting?}

We addressed this question by investigating the temporal trends in individual GPAs for students who 
a)

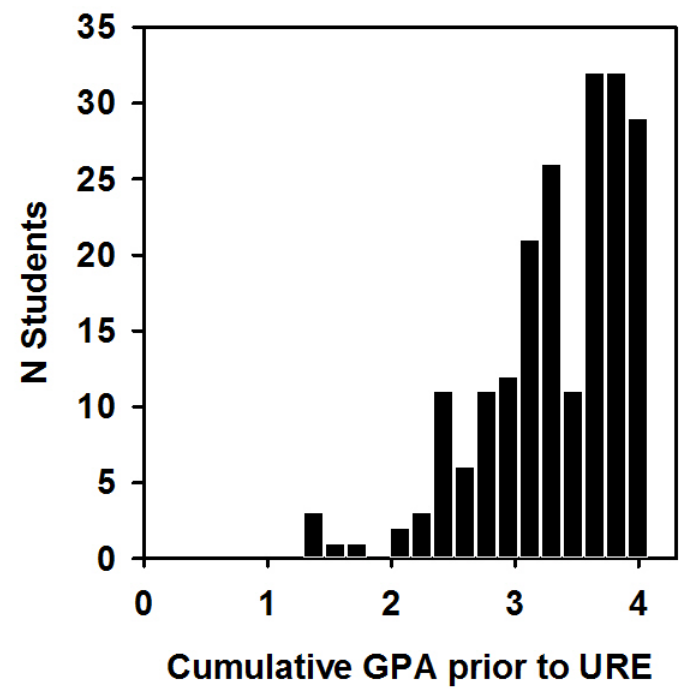

Figure 1a

Frequency distribution of students' GPA prior to an undergraduate research experience

enrolled in an independent studies course exclusively during their third year $(\mathrm{N}=18)$ and those from a cohort of comparable size $(\mathrm{N}=20)$ who did not enroll in an independent studies course during their entire degree program. Our sample size here is smaller than in our previous analyses because many students take UREs in their fourth year, which we excluded in order to focus on the lasting effects of UREs beyond the year in which they were taken. We used one-way repeated measures analysis of variance to compare GPAs between years of study.

In both groups, students' GPAs increased from year two to four (Figure 3). Overall, there were significant differences in GPA among the year levels for both groups ( $\mathrm{P}=0.005$ for URE students and $\mathrm{P}=0.006$ for students with no independent studies course), and our results indicate that the effects of the URE on GPA lasted beyond the year during which the directed studies took place since there were no significant differences in GPA for students with URE between years three and four. In contrast, the GPA of the control group was significantly higher in year four than it was in year three $(\mathrm{P}=0.027)$. b)

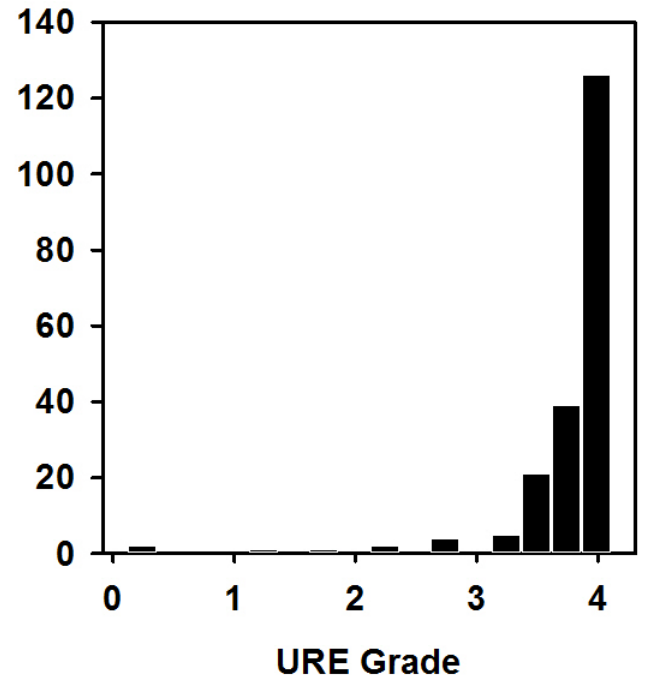

Figure 1b

Frequency distribution of final grades in undergraduate research experience

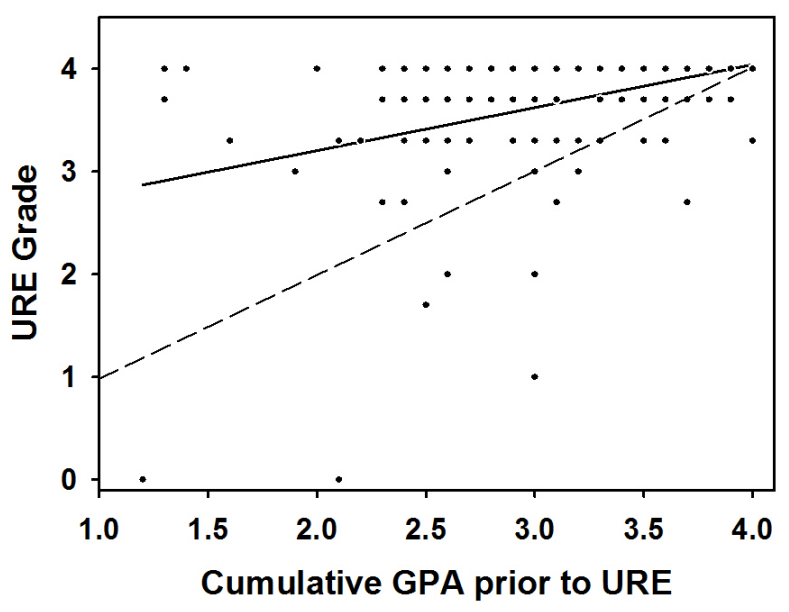

Figure 2

Relationship between students' final grade in an undergraduate research experience and their prior cumulative GPA ${ }^{1}$

\footnotetext{
${ }^{1}$ The solid line represents the actual linear regression among the data points, $\mathrm{r} 2=0.18, \mathrm{p}<0.001, \mathrm{n}=201$ (duplicate data points do not show on the graph). The dashed line represents what the linear regression would have been if the URE final grade had equaled the prior GPA.
} 
Students without URE

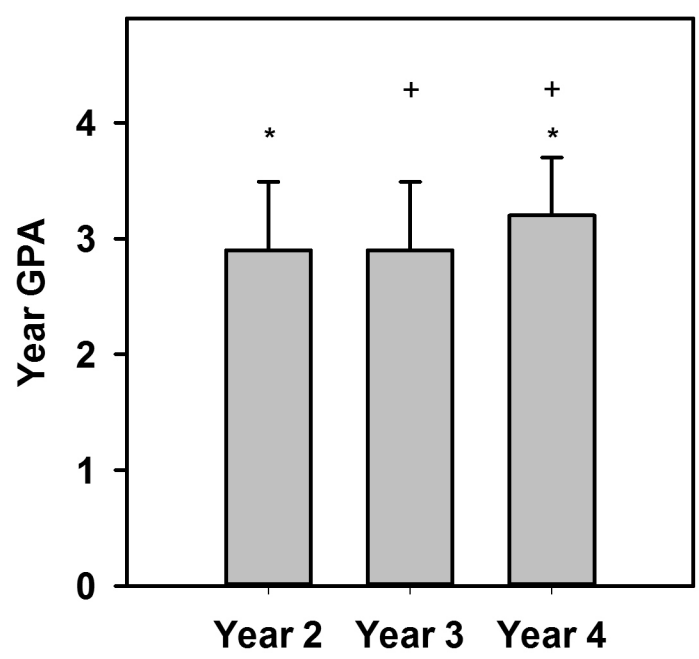

Students with URE

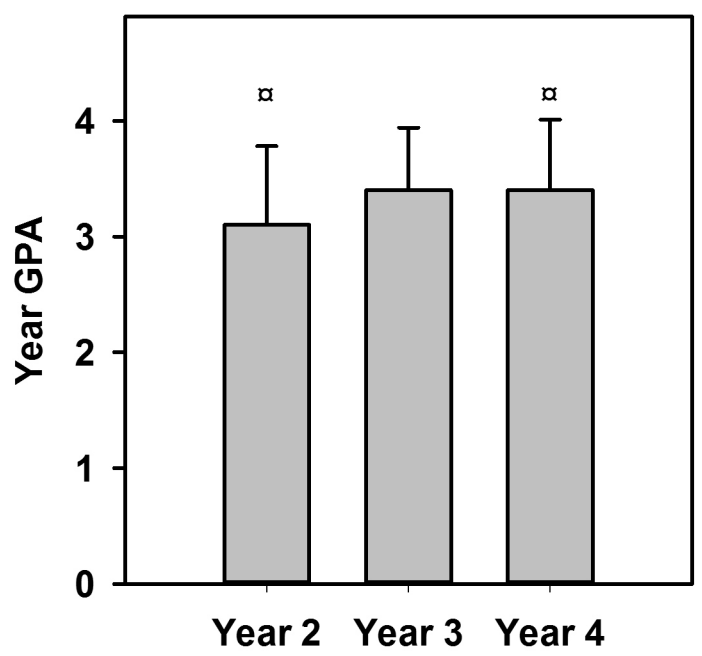

Figure 3

Current year's GPA for students with and without an undergraduate research experience in year three of their undergraduate studies ${ }^{2}$

\section{Conclusions}

Being admitted to independent studies courses is often reserved for students with outstanding grades with the assumption that prior academic success is a sufficient predictor of success in undergraduate research. However, our data reveals that the majority of students with lower than average GPA earned relatively high grades in those research courses, hence receiving accrued benefits from the experience (Figure 2). Admission to UREs based only on prior GPA thus appears to be counter-productive by denying access to high impact educational experiences from students who would most benefit from it.

In addition, students' GPAs in the year the independent studies course is completed are higher relative to students who do not enroll in independent studies (Figure 3), but the GPAs of students without independent studies rise to the same level in the subsequent year. Essentially, undergraduate research seems to raise student GPA a year earlier. These results agree with previous studies in that undergraduate research has a positive impact on student GPA, but the effect seems to be initiated during the year in which students are enrolled in independent studies (Fechheimer et al., 2011; Kinkel \& Henke, 2006).
Thus, similar to Kinkel and Henke's (2006) conclusions, it appears that the impact of UREs on students GPA is not solely due to a high grade in the URE but rather to a general improvement in academic performance across many disciplines. Others have shown that the more UREs a student encounters, the greater the increase in graduating GPA (Fechheimer et al., 2011). A key difference in our study is that we compared GPA for individual years, not the graduating GPA. It may be that the effect Fechheimer et al. (2011) noted in students' graduating GPA is due to their GPA rising in an earlier year than students who do not enroll in an independent studies course. Increased GPA during the year that a student is enrolled in undergraduate research has also been observed at other institutions (Marcus et al., 2010). Together, our results suggest two things:

1. Enrolment in undergraduate research should not be limited to students with superior GPA when the goal is to promote success through engagement.

2. Undergraduate research should be made available in earlier years and not only in students' senior years.

\footnotetext{
${ }^{2}$ Significant differences were found between years 2 and $4\left(^{*}\right)$ and years 3 and $4(+)$ for students who never engaged in an URE and between years 2 and 4 (a) for students who completed an URE.
} 
When considering the implications of our study, the context in which the data were gathered must be considered. Augustana is a rural campus of approximately 1000 students that houses a Liberal Arts and Sciences Faculty of the University of Alberta. Thus, the student data analyzed for this study is a relatively small set that includes students from various disciplines in both the Arts and Sciences. In addition, ours is a correlative study that assesses a possible relationship between students' final grade in an undergraduate research experience (defined as an independent studies course in this paper), students' GPA before completion of the undergraduate research experience and students' GPA in the subsequent year. It is important to note that other mitigating factors can and will influence student GPA and final grades in individual courses (e.g., differences in textbooks, instructors, student cohort ability, classrooms, learning technologies, etc.). However, for the purposes of this study, we only considered differences in students' grades between those students who completed an undergraduate research experience and those that did not. Our data suggests that UREs may positively impact students' academic performance.

A recent study suggests that the benefits of undergraduate research last far beyond students' undergraduate education extending into their career for those who pursue science after completion of their bachelor's degree (Harsh, Maltese, \& Tai, 2011). It is interesting, however, that during the undergraduate research experience studies have reported that faculty and students have slight differences in their perception of the benefits being accrued. Although both faculty and students rated improving thinking skills and working like a scientist high, students rated intellectual and personal development higher than socialization into science, whereas faculty reversed this relative rating, suggesting that faculty and students have slightly different perceptions of the role of undergraduate research in students' academic and personal development (Hunter, Laursen, \& Seymour, 2007). Regardless, there is strong support in the literature for the high impact that undergraduate research has on student learning outcomes, preparedness for subsequent careers and raising course grades (Brownell \& Swaner, 2010; Junge, Quinones, Kakietek, Teodorescu, \& Marsteller, 2010). Thus, it appears to be counter-productive to deny access to high impact educational experiences to students who would most benefit from them.

\section{References}

Brongo Pacifici, L. \& Thomson, N. (2011). What do they expect? A comparison of student expectations and outcomes of undergraduate research experiences. Journal of College Science Teaching, 41, 54-59.

Brownell, J.E., \& Swaner, L.E. (2010). Undergraduate research. In Five high-impact practices: Research on learning outcomes, completion, and quality (pp 3136). Washington, DC: Association of American Colleges and Universities.

Fechheimer, M., Webber, K., \& Kleiber, P.B. (2011). How well do undergraduate research programs promote engagement and success of students? CBE: Life Sciences Education, 10, 156-163.

Harde, R., \& Haave, N. (2012). Wider horizons: fostering a culture of undergraduate research. Collected Essays on Learning and Teaching, 5, 39-43.

Harsh, J.A., Maltese, A.V., \& Tai, R.H. (2011). Undergraduate research experiences from a longitudinal perspective. Journal of College Science Teaching, 41, 84-91.

Hunter, A.B., Laursen, S.L., \& Seymour, S. (2007). Becoming a scientist: the role of undergraduate research in students' cognitive, personal, and professional development. Science Education, 91, 36-74.

Jonides, J. (1995). Evaluation and dissemination of an undergraduate program to increase retention of at-risk students. Washington, DC: Fund for the Improvement of Post-Secondary Education.

Junge, B., Quinones, C., Kakietek, J., Teodorescu, D., \& Marsteller, P. (2010). Promoting undergraduate interest, preparedness, and professional pursuit in the sciences: an outcomes evaluation of the SURE program at emory university. CBE: Life Sciences Education, 9, 119-132.

Kinkel, D.H. \& Henke, S.E. (2006). Impact of undergraduate research on academic performance, 
educational planning, and career development. Journal of Natural Resources and Life Sciences Education, 35, 194-201.

Kuh, G.D. (2008). High-impact educational practices: What they are, who has access to them, and why they matter. Washington, DC: Association of American Colleges and Universities.

Lopatto, D. (2007). Undergraduate research experiences support science career decisions and active learning. CBE Life Sciences Education, 6, 297306.

Marcus, J.M., Hughes, T.M., \& McElroy, D.M. (2010). Engaging first-year undergraduates in handson research experiences: The upper green river barcode of life project. Journal of College Science Teaching, 39, 39-45.

Nagda, B.A., Gregerman, S.R., Jonides, J., Von Hippel, W., \& Lerner, J.S. (1998). Undergraduate student-faculty research partnerships affect student retention. The Review of Higher Education, 22, 55-72.

Sadler, T.D. \& McKinney, L. (2010). Scientific research for undergraduate students: A review of the literature. Journal of College Science Teaching, 39, 43-49.

Seymour, E., Hunter, A.B., Laursen, S.L. \& Deantoni, T. (2004). Establishing the benefits of research experiences for undergraduates in the sciences: first findings from a three-year study. Science Education, 88, 493-534.

\section{Acknowledgements}

Thanks to Joyce McEachern for gathering the data.

\section{Biographies}

Neil Haave is Associate Professor at the Augustana Campus of the University of Alberta where he has been teaching biochemistry, cell biology, and history and philosophy of biology since 1990. As Associate Dean (Teaching) he is interested in raising the profile of, and increasing student participation in, undergraduate research.

Doris Audet is Associate Professor at the Augustana Campus of the University of Alberta where she teaches courses related to vertebrate zoology, animal behaviour and conservation biology. Her overarching goal as an undergraduate educator is to promote the integration of teaching and research in order to engage students in the scientific process in as many ways as possible. 